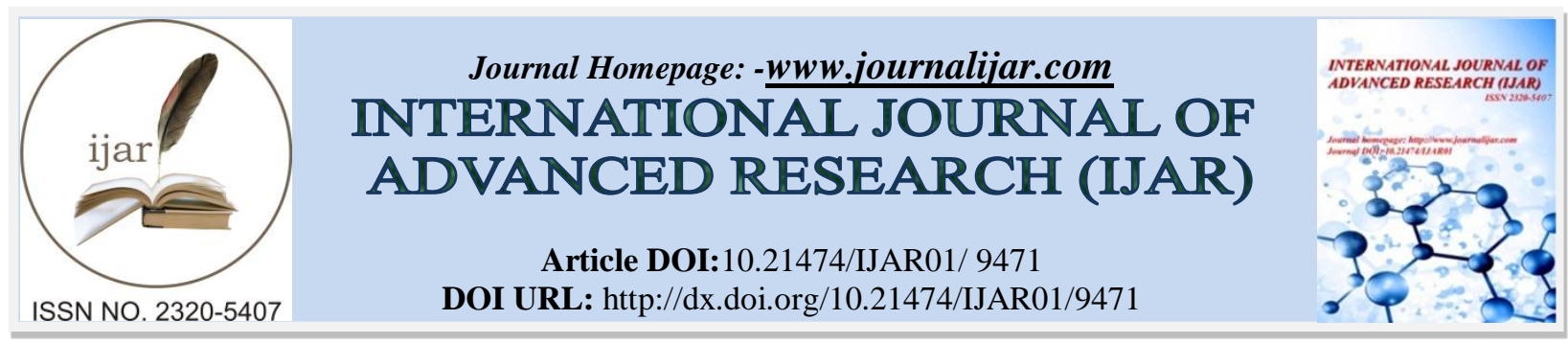

RESEARCH ARTICLE

\title{
COMPARATIVE STUDIES OF STOMATA OF ALOE RAUHII REYNOLDS AND GASTERIA ARMSTRONGII SCHOENL.
}

Sameer Gunjan Lakra ${ }^{1}$ and Kamini Kumar ${ }^{2}$.

1. Research Scholar, Laboratory of Cytogenetics, Plant Breeding, Molecular Biology and Plant BioTechnology,University Department of Botany, Ranchi University, Ranchi-834008 Jharkhand, India.

2. University Professor, Pro-V. C. (On Lien), University Department of Botany, Ranchi University, Ranchi834008 Jharkhand, India.

\section{Manuscript Info}

.........................

Manuscript History

Received: 02 June 2019

Final Accepted: 04 July 2019

Published: August 2019

Key words:-

Aloe, Gasteria, Stomata, Stomatal Index, Tetracytic.

\section{Abstract}

In the present investigation two succulents, Aloe rauhii Reynolds and Gasteria armstrongii Schoenl, of family Asphodelaceae were considered for the comparative stomatal studies. The results obtained after studies showed that both the genera have tetracytic stomata. The maximum stomatal index was recorded in the apex portion of adaxial surface $(15.205 \pm 1.06 \mu)$ in Gasteria armstrongii Schoenl. The longest $(45.3 \pm 0.76 \mu)$ and the widest $(46.5 \pm 0.64 \mu)$ stomata were also recorded in Gasteria armstrongii Schoenl. It was concluded that both genera are closely related and the rate of transpiration is higher in Gasteria armstrongii Schoenl as compared to Aloe rauhii Reynolds.

Copy Right, IJAR, 2019,. All rights reserved.

\section{Introduction:-}

The two plants Aloe rauhii Reynolds and Gasteria armstrongii Schoenl are succulents belong to the family Asphodelaceae and sub family Alooideae. Aloe rauhii Reynolds is endemic to Madagacar whereas Gasteria armstrongii Schoenl is a native to South Africa. Its flowers are stomach or bell shaped and are orange in color.

Aloe has been used for its cathartic, stomachic and anthelminthic properties (Chopra and Ghosh, 1938) and to treat leprosy and peptic ulcer (Diez-Martinez, 1981). It has been used by many pharmaceutical companies and by traditional practitioners in many traditional treatments (Mabberley, 1987).

In South Africa, Gasteria species was used against bad spirit and lightening (Philander, 2011). Traditionally, some species of these plants are used in the management of fungal infections in HIV/AIDS patients. It exhibits good amount of phenolic contents and antioxidant activity (Wilfred et al., 2012). It is also helpful in the treatment of paralysis (Van-Jaarsveld et al., 1994).

The present investigation on Aloe rauhii Reynolds and Gasteria armstrongii Schoenl was carried out to determine the shape, size and frequency of stomata and its variations in leaf epidermis. This will allow us to establish a taxonomic relationship between the two genera since size of stomata also plays a crucial role in cytological criteria besides karyotype (According to De Wet, 1954).

Corresponding Author:-Sameer Gunjan Lakra. 


\section{Materials And Methods:-}

The plants were collected from Ahmedabad, Gujarat. Fresh leaves were taken for stomatal studies. The collected leaves were divided into three portions i.e. apex, middle and base, from both the surfaces. It was done by scratching the epidermal surface with sharp razor (Topno and Ghosh, 1997). Scratched epidermis was then stained with safranin and mounted with glycerin. It was observed under microscope and necessary measurement was done with the help of stage micrometer and ocular micrometer. The Stomatal Index was calculated by using the following formula:

$$
\text { Stomatal Index }=\frac{\text { Number of stomata per unit area }}{\text { Number of stomata }+ \text { Number of epidermal cells }} \times 100
$$

\section{Results:-}

In this investigation, tetracytic or kidney shaped stomata was observed in both the genera (Wilfred et al.,2014; Brandham, and Cutler, 1978.)(Fig. 3 and 4). In Aloe rauhii Reynolds, Stomatal Index was recorded maximum at the basal region of adaxial surface $(14.48 \pm 0.74 \mu)$ and minimum at the apex portion of abaxial surface $(8.43 \pm 0.73 \mu)$ while in Gasteria armstrongii Schoenl, maximum Stomatal Index was found at the apex region of adaxial surface $(15.205 \pm 1.06 \mu)$ and minimum at the apex region of abaxial surface $(8.16 \pm 0.74 \mu)$ [Table-1] [Fig. 5A and 5B]. In Aloe rauhii Reynolds, longest stomata was observed at the basal region of abaxial surface $(41.7 \pm 3.90 \mu)$ and smallest at the basal region of adaxial surface $(27.9 \pm 1.12 \mu)$ whereas in Gasteria armstrongii Schoenl, longest stomata was observed at the basal portion of adaxial surface $(45.3 \pm 0.76 \mu)$ and smallest at the middle portion of adaxial surface $(38.7 \pm 1.37 \mu)$ [Table-1] [Fig. 6A, 6B, 7A and 7B]

In Aloe rauhii Reynolds, maximum width of stomata was observed at the apex region of abaxial surface $(33.9 \pm 1.12$ $\mu)$ and minimum width at the basal portion of adaxial surface $(28.2 \pm 0.75 \mu)$ while in Gasteria armstrongii Schoenl, stomata with maximum width was recorded at the basal region of adaxial surface $(46.5 \pm 0.64 \mu)$ and minimum width at the middle portion of adaxial surface $(25.2 \pm 1.81 \mu)$ [Table-1][Fig. 6A, 6B, 7A and 7B].

\section{Discussion:-}

Kidney shaped or tetracytic stomata were found in both the species of Aloe rauhii Reynolds and Gasteria armstrongii Schoenl which was surrounded by guard cells and subsidiary cells. The stomata were deeply sunken which point out its status of drought resistant plant or plants growing under stressed condition. Leaves of both the plants were amphistomatic with differences in their stomatal frequency, stomatal length and stomatal width. These parameters are important in drought resistant plants. The size of the stomata can also be correlated with the genome size within the angiosperms (Hadgson, 2010). In the present investigation, maximum stomatal index, length and width was recorded in Gasteria armstrongii Schoenl when compared with Aloe rauhii Reynolds which shows that the transpiration rate is, maybe, higher in Gasteria armstrongii Schoenl.

On the basis of above findings it maybe concluded that both plants Aloe rauhii Reynolds and Gasteria armstrongii Schoenl are closely related from taxonomic point of view since both are amphistomatic and bear same type or shape of stomata which were deeply sunken.

\section{Acknowledgement:-}

We express our sincere gratitude to Prof. Ashok Kumar Choudhary, Head, University Department of Botany, Ranchi University, Ranchi for providing the laboratory facilities.

Table 1:-Stomatal Index data and data related to length and width of stomata (in $\mu$ ) of adaxial and abaxial surface of Aloe rauhii Reynolds and Gasteria armstrongii Schoenl.

\begin{tabular}{|c|c|c|c|c|c|c|c|c|c|c|}
\hline \multirow{3}{*}{ Surface } & \multirow{3}{*}{ Plant } & \multicolumn{4}{|c|}{ Apex } & \multicolumn{4}{c|}{ Middle } & \multicolumn{4}{c|}{ Base } \\
\cline { 3 - 11 } & & S.I. & $\begin{array}{c}\text { Length } \\
(\mu)\end{array}$ & $\begin{array}{c}\text { Width } \\
(\mu)\end{array}$ & S.I. & $\begin{array}{c}\text { Length } \\
(\mu)\end{array}$ & $\begin{array}{c}\text { Width } \\
(\mu)\end{array}$ & $\begin{array}{c}\text { S.I. } \\
\text { Length } \\
(\mu)\end{array}$ & $\begin{array}{c}\text { Width } \\
(\mu)\end{array}$ \\
\hline \multirow{4}{*}{ Adaxial } & & 13.47 & 30 & 30.6 & 9.36 & 30 & 31.2 & $\mathbf{1 4 . 4 8}$ & $\mathbf{2 7 . 9}$ & $\mathbf{2 8 . 2}$ \\
& Aloe & \pm & \pm & \pm & \pm & \pm & \pm & \pm & \pm & \pm \\
& rauhii & 0.66 & 0 & 1.18 & 0.12 & 1.2 & 1.14 & $\mathbf{0 . 7 4}$ & $\mathbf{1 . 1 2}$ & $\mathbf{0 . 7 5}$ \\
\cline { 2 - 11 } & & $\mathbf{1 5 . 2 0 5}$ & 44.7 & 36 & 14.676 & $\mathbf{3 8 . 7}$ & $\mathbf{2 5 . 2}$ & 6.99 & $\mathbf{4 5 . 3}$ & $\mathbf{4 6 . 5}$ \\
& Gasteria & $\mathbf{\pm}$ & \pm & \pm & \pm & \pm & \pm & \pm & \pm & \pm \\
& armstrongii & $\mathbf{1 . 0 6}$ & 0.66 & 1.12 & 0.80 & $\mathbf{1 . 3 7}$ & $\mathbf{1 . 8 1}$ & 0.18 & $\mathbf{0 . 7 6}$ & $\mathbf{0 . 6 4}$ \\
\hline
\end{tabular}




\begin{tabular}{|c|c|c|c|c|c|c|c|c|c|c|}
\hline \multirow[t]{2}{*}{ Abaxial } & $\begin{array}{l}\text { Aloe } \\
\text { rauhii }\end{array}$ & $\begin{array}{c}8.43 \\
\pm \\
0.73\end{array}$ & $\begin{array}{c}33 \\
\pm \\
0.73 \\
\end{array}$ & $\begin{array}{c}33.9 \\
\pm \\
1.12\end{array}$ & $\begin{array}{c}9.21 \\
\pm \\
0.85\end{array}$ & $\begin{array}{c}30 \\
\pm \\
0.85\end{array}$ & $\begin{array}{c}30.9 \\
\pm \\
1.04\end{array}$ & $\begin{array}{c}8.65 \\
\pm \\
0.89\end{array}$ & $\begin{array}{c}41.7 \\
\pm \\
3.90\end{array}$ & $\begin{array}{c}32.1 \\
\pm \\
2.2\end{array}$ \\
\hline & $\begin{array}{c}\text { Gasteria } \\
\text { armstrongii }\end{array}$ & $\begin{array}{c}8.16 \\
\pm \\
0.74\end{array}$ & $\begin{array}{c}45 \\
\pm \\
1.34\end{array}$ & $\begin{array}{c}36.3 \\
\pm \\
1.16\end{array}$ & $\begin{array}{c}12.064 \\
\pm \\
1.1\end{array}$ & $\begin{array}{c}42 \\
\pm \\
0.85\end{array}$ & $\begin{array}{c}26.4 \\
\pm \\
1.18\end{array}$ & $\begin{array}{c}13.39 \\
\pm \\
0.78\end{array}$ & $\begin{array}{c}41.7 \\
\pm \\
1.67\end{array}$ & $\begin{array}{c}36.3 \\
\pm \\
2.05\end{array}$ \\
\hline
\end{tabular}

Photographs of Aloe rauhii Reynolds (Fig. 1) and Gasteria armstrongii Schoenl (Fig. 2).

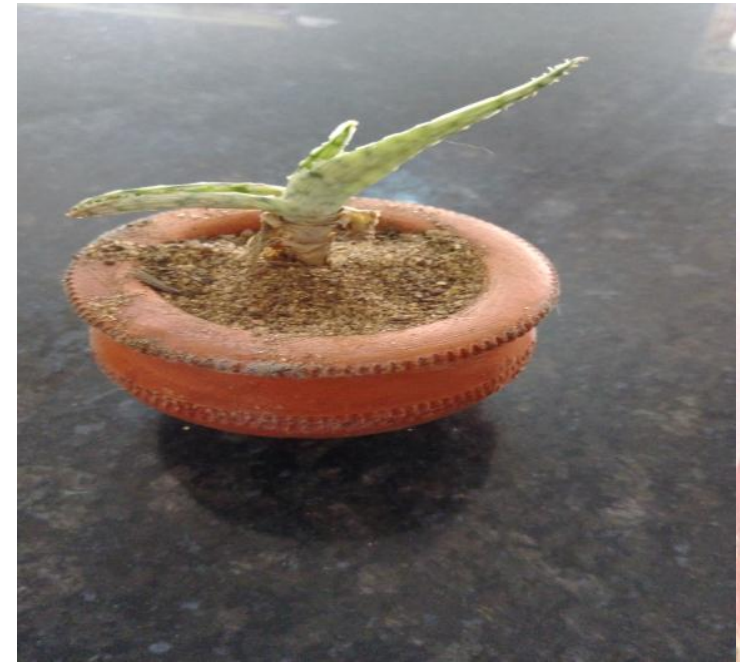

Fig 1

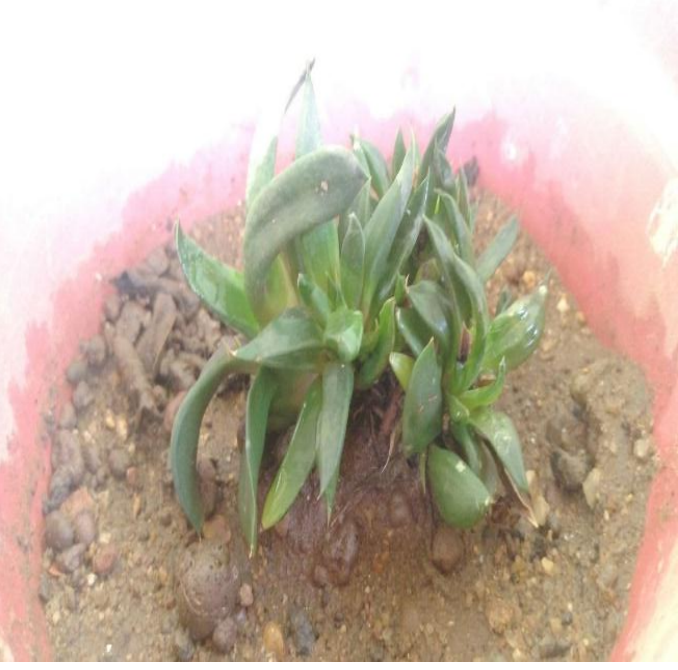

Fig 2

Photomicrographs of stomata of Aloe rauhii Reynolds (Fig. 3) and Gasteria armstrongii Schoenl (Fig. 4).

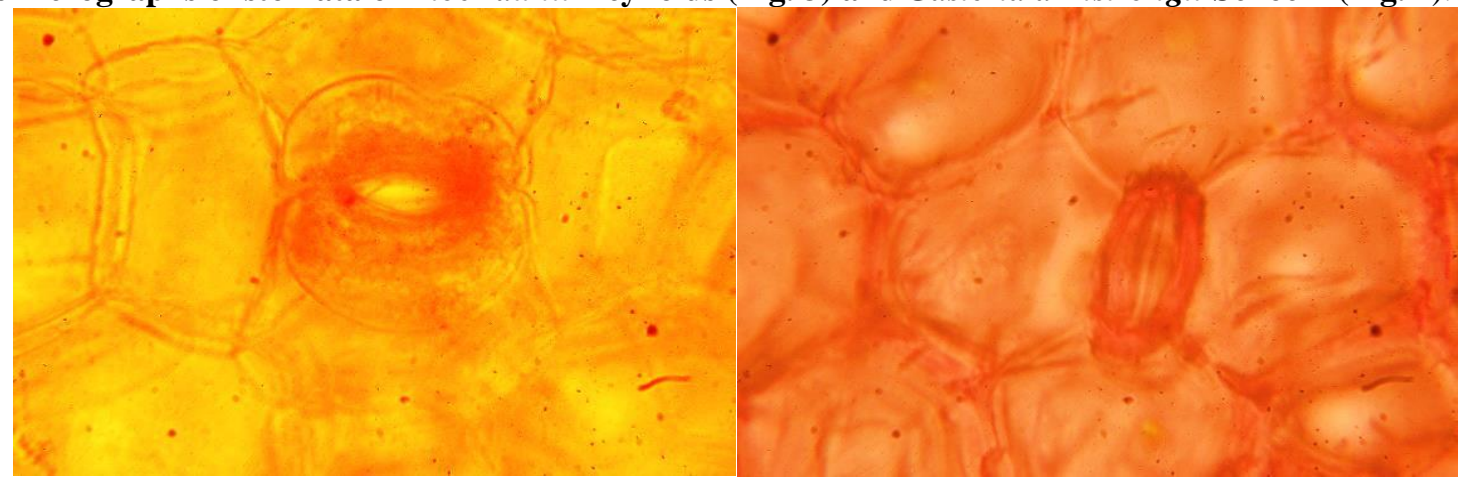

Fig 3

Fig 4 
Fig 5:-Column graph showing stomatal index of Aloe rauhii Reynolds and Gasteria armstrongii Schoenl in adaxial surface (Fig. 5A) and abaxial surface (fig. 5B).

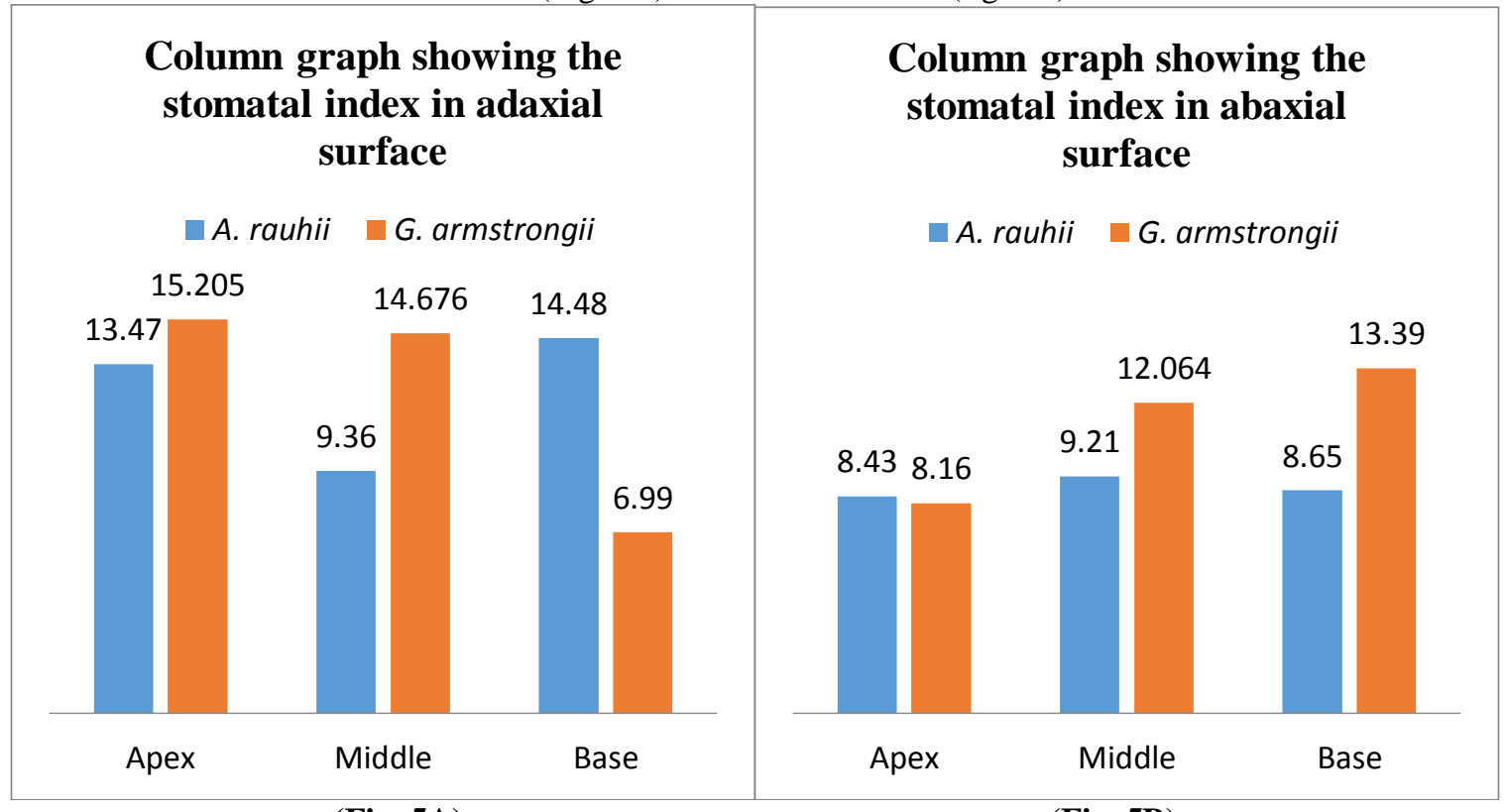

(Fig. 5A)

(Fig. 5B)

Fig 6:-Column graph showing length (Fig. 6A) and width (Fig. 6B) of stomata of Aloe rauhii Reynolds and Gasteria armstrongii Schoenl.

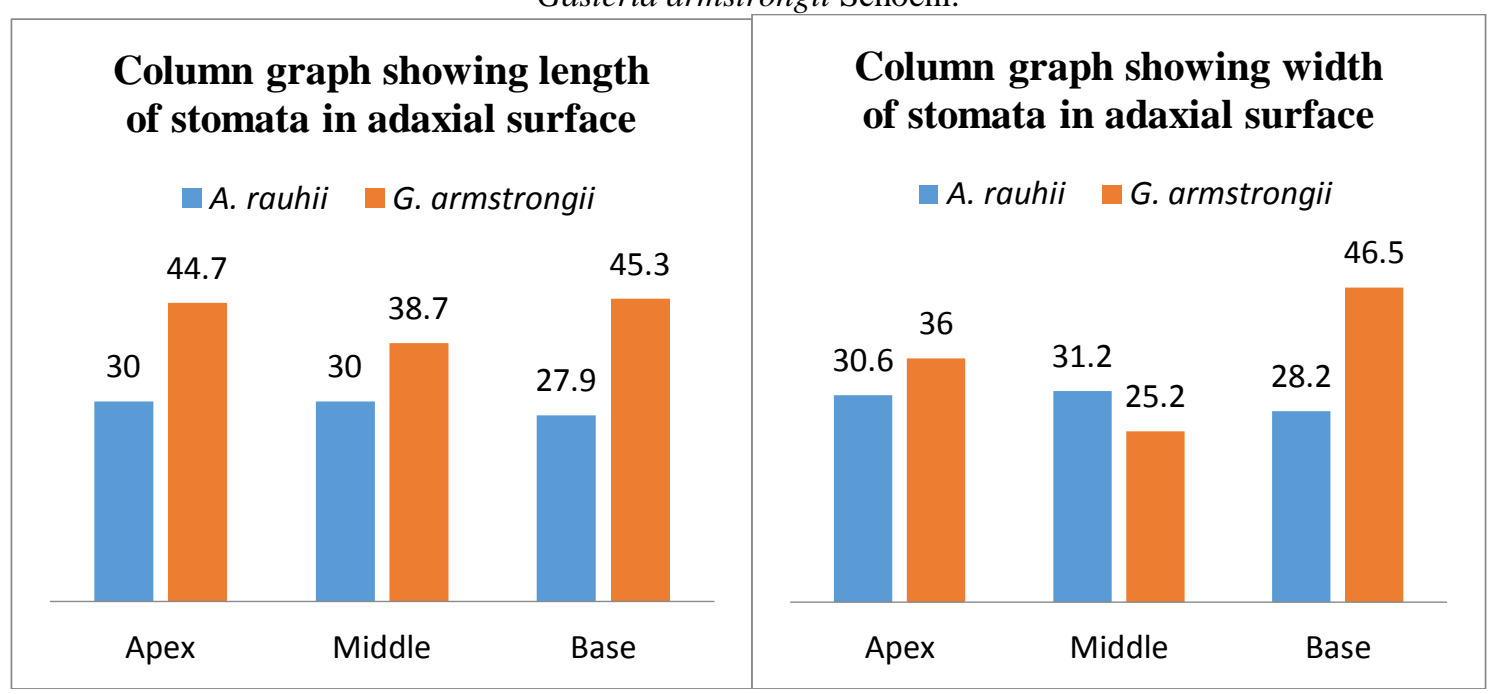

(Fig. 6A)

(Fig. 6B) 
Fig. 7: Column graph showing length (Fig. 7A) and width (Fig. 7B) of stomata of Aloe rauhii Reynolds and Gasteria armstrongii Schoenl.

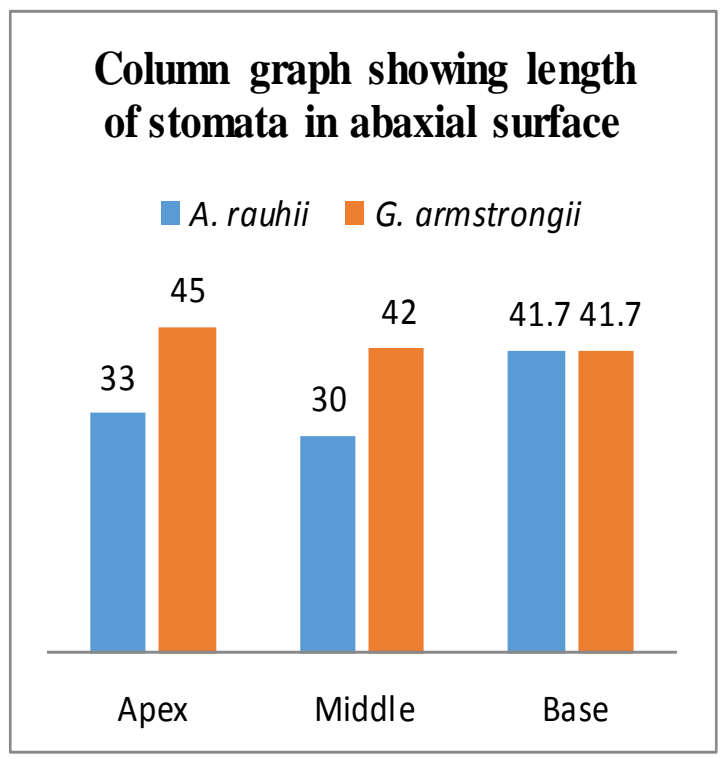

(Fig. 7A)

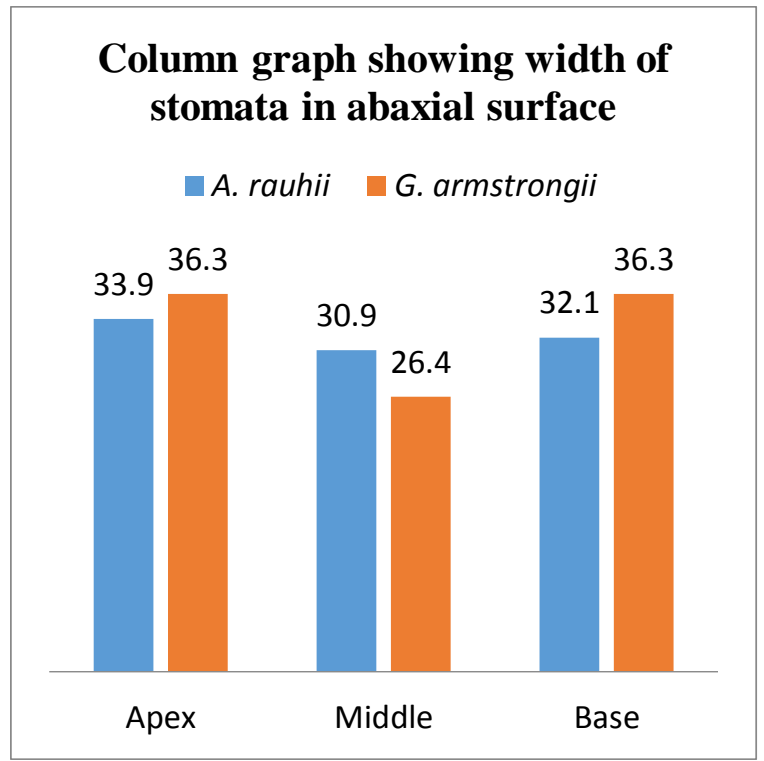

(Fig. 7B)

\section{References:-}

1. Brandham, P.E. and Cutler, D.F. (1978). Influence of chromosome variations on the organization of the leaf epidermis in hybrid Aloe (Liliaceae), Bot. J Linnean Soc. 77: 1-16.

2. Chopra, R.N. and Ghosh, N.N. (1938). Chemische Untersuchung der indischen Aloearten Aloe vera, Aloe India, Boyle, Archiv. Der. Pharmazie. 276: 348-350.

3. De Wet, M.J. (1954). Stomatal size as a cytological criterian in Danthonia, Cytologia. 19: 176-181.

4. Diez-Martinez, S.D. (1981). La Zabila. Communicado No. 46 sobre recursos bioticos potenciales del pais. INIREB, Mexico.

5. Hadgson, J.G. (2010). Stomatal vs. Genome size in angiosperms: the somatic tail wagging the genomic dog? Annals of Botany. 105: 573-584.

6. Mabberley, D.J. (1987). The Plant Book: A portal dictionary of the higher plants." Cambridge University Press, Cambridge. 21.

7. Philander, L.A. (2011). An ethnobotany of Western Cape Rasta bush medicine, Journal of Ethnopharmacology. 138: 578-594.

8. Topno and Ghosh, T.K. (1997). Comparision of epidermal character of Cassia Linn., Columban J. Life Sci. 5.1 and 2: 239-242.

9. Van-Jaarsveld, E.J., Smith, G.F. and Ben-Erk, V.W. (1994). A cladistics analysis of Gasteria (Aloaceae), South African Journal of Sciences. 90: 467-476.

10. Wilfred, M.O., Grierson, D.S. and Ndip, R.N. (2012). Phytochemical studies and antioxidant activity of two South African medicinal plants traditionally used for the management of opportunistic fungal infections in HIV/AIDS patients, BMC Complementary and Alternative Medicines. 12: 43-49.

11. Wilfred, M.O., Grierson, D.S. and Ndip, R.N.. (2014). Foliar micro-morphology of Gasteria bicolor Haw. (Asphodelacece) from South Africa, Afr. J. Tradit. Complement. Altern. Med. 11(4): 71-76. 